\title{
AN INCIDENTAL FINDING OF NUTCRACKER PHENOMENON ON HRCT THORAX SCAN IN A YOUNG MALE PATIENT-A CASE REPORT.
}

KEY WORDS:

\section{Dr Aditya Sane*}

\section{Dr Sarfaraz}

\section{Shaikh}

MD Radiodiagnosis junior resident, Dr DY Patil Medical college \& Hospital Navi Mumbai. *Corresponding Author

MD Radiodiagnosis Assistant professor, Dr DY Patil Medical college \& Hospital Navi Mumbai. compression of the left renal vein between the SMA and the aorta, with impaired blood outflow often accompanied by distention of the proximal portion of the vein. [2]

Although uncommon, it can clinically manifest with intermittent hematuria, dysuria, flank or abdominal pain. It may be asymptomatic for long period and constitute casual findings. Ultrasound is the first-line imaging which require more accurate study with contrast-enhanced computed tomography.[1,2]

\section{INTRODUCTION:}

Nutcracker syndrome (NCS) is caused by compression of the left renal vein (LRV) between the aorta and the superior mesenteric artery (SMA) where it passes in the fork formed at the bifurcation of these arteries. [1]

In Nutcracker phenomenon there is no clinical symptoms of nutcracker syndrome but one can find compression of the left renal vein between SMA and Aorta with proximal dilatation of the left renal vein.

Herein, we report a case Nutcracker Phenomenon as an incidental finding on HRCT Thorax scan in a young male patient.

\section{Case report:}

A 19-year-old male presented to hospital with complains of chest pain (right side), fever, cough, with weight loss and intermittent abdominal pain since 2 months.

He was referred to our radiology department and underwent HRCT (Plain + Contrast) scan/ CT of the thorax using GE CT 128 slice scanner.

CT scan revealed a large relatively well defined heterogeneously enhancing sub pleural soft tissue density lesion with spiculated margins in the right middle lobe with abrupt cut off involving the segmental bronchus with no evidence of calcification or necrosis within. There was no evidence of bony erosion or intravascular extension.

It also showed mild right sided pleural effusion with passive atelectasis and fissural extension with interlobular septal thickening with minimal streak of fluid in the left pleural cavity. Mediastinal lymphadenopathy was also detected.

Also, a reduced aorto-mesenteric angle with compression of the traversing left renal vein was observed.

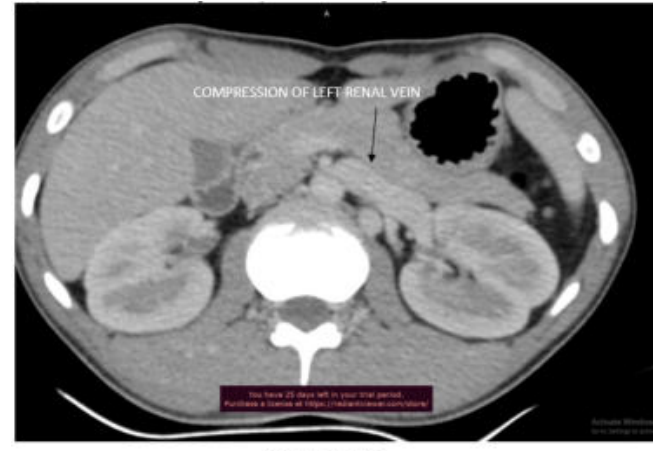

AXIAL VIEW

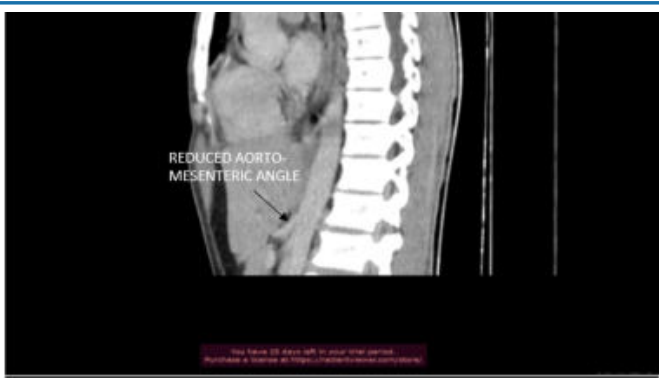

\section{DISCUSSION:}

Nutcracker syndrome (NCS) was first described in 1950 by El Sadr and Mina.[3] In 1972, de Schepper gave the name "nutcracker syndrome" to the disease, [4] as the LRV between the aorta and the SMA resembled a nut between the jaws of a nutcracker.

NCS is classified as either anterior or posterior. The anterior NCS, which is the most common, is defined by the compression of the LRV between the aorta and the SMA. [1,2]

It can be often recognized by correlating imaging findings to the clinical presentation. More challenging is the diagnosis of the nutcracker phenomenon due to the lack of symptoms and in fact often an occasional detection during routine imaging studies. $[5,6,7,8,9]$

In this case, the patient had come for primarily for investigation of Thorax related symptoms, however we were able to diagnose the nutcracker phenomena on CT thorax scan as the slices are usually taken from apex of the lungs till the hilum of kidneys.

Hence, we were able to incidentally estimate the anterior nutcracker phenomenon on CT scan. Studies in literature have found similar incidental finding of nutcracker syndrome on CT scan in asymptomatic population. $[6,7,8,9]$

Work up for NCS includes a series of tests such as Doppler ultrasound (DUS), CT scan, magnetic resonance imaging, angiography and retrograde phlebography. $[1,2,5,10]$

Usually Ultrasonography is a good primary imaging modality, $\mathrm{Ct}$ scan is able to show the compression of the left renal vein between the aorta and superior mesenteric artery and the coexistence of abnormal venous collaterals. $[5,6,9,10]$

The management of Nutcracker Syndrome depends upon the clinical presentation and the severity of the left renal vein hypertension with options ranging from simple surveillance to surgical interventions. $[1,2,5]$ 


\section{CONCLUSION:}

The NCP and NCS are rare disease entities. It may be totally asymptomatic, often diagnosed as a transient incidental finding in medical imaging studies .

It represents a challenge in terms of accurate diagnosis and management.

CT scan can be a reliable diagnostic modality.

\section{REFERENCES:}

1. Ananthan K, Onida S, Davies AH. Nutcracker Syndrome: An Update on Current Diagnostic Criteria and Management Guidelines. Eur J Vasc Endovasc Surg. 2017;53(6):886-894.

2. Kurklinsky AK, Rooke TW. Nutcracker phenomenon and nutcracker syndrome. Mayo Clin Proc. 2010;85(6):552-9.

3. El-Sadr AR, Mina E. Anatomical and surgical aspects in the operative management of varicocele. Urol Cutaneous Rev. 1950;54:257-62.

4. de Schepper A. "Nutcracker" phenomenon of the renal vein and venous pathology of the left kidney.J Belge Radiol. 1972;55:507-11.

5. Ahmed K, Sampath R, Khan MS. Current trends in the diagnosis and management of renal nutcracker syndrome:a review.EurJVasc Endovasc Surg.2006;31:410-6.

6. Cuellar I Calabria H, Quiroga Gomez S, Sebastia Cerqueda C, et al. Nutcracker or left renal vein compression phenomenon: multidetector computed tomography findings and clinical significance. Eur Radiol.2005; 15:1745Y1751.

7. Ali-El-Dein B, Osman Y, Shehab El-Din AB, et al. Anterior and posterior nutcracker syndrome: a report on 11 cases. Transplant Proc. 2003;35:851Y853

8. Grimm LJ, Engstrom BI, Nelson RC, Kim CY. Incidental detection of nutcracker phenomenon on multidetector CT in an asymptomatic population: prevalence and associated findings.J Comput Assist Tomogr.2013;37(3):415-8.

9. Sataa S, Chekib K, Riadh M, Hamza E. Nutcracker syndrome as an incidental finding on computed tomography scan after blunt abdominal trauma. Tunis Med.2012 Feb;90(2):192-5.

10. Kim SH. Doppler US and CT Diagnosis of Nutcracker Syndrome. Korean J Radiol.2019;20(12):1627-1637. 